\title{
Cross Cultural Conflict Management - An Adaptive Co-Management Perspective
}

\section{Ruiyang Wei*}

SILC Business School, Shanghai University No.20 Cheng Zhong Road, 201899 Shanghai, P.R.China.

Keywords: Adaptive Co-Management (ACM), conflict, FAW-Volkswagen, China

\begin{abstract}
The idea of 'globalization' has attracted increasing attention among companies and investors. As one of the most common ways available for companies to enter the foreign markets, joint ventures can provide great help in terms of resource sharing, complementary advantages, reasonable and legal reduction of financial expenditures and operating cost. However, the possible negative outcomes such as serious cross-cultural conflicts may greatly reduce the effectiveness and advantages of joint ventures. Adaptive Co-Management (ACM) theory may help dealing with problems related to cross-cultural conflicts and thus leads to better operation. This essay focuses on studying the effectiveness of applying ACM to cross-culture conflict management. An analysis on the culture and conflict management methods of FAW-Volkswagen will be taken as the object for this research. To make the study more concrete, the cases of Audi's sales division are introduced to represent FAW-Volkswagen's culture management policies. A comparison between the methods FAW-Volkswagen have taken and ACM theory is taken to consider their similarity and seek for the possibility of further application of the theory within FAW-Volkswagen. The data and cases displayed in the paper are sourced from the company's official website and former researches.
\end{abstract}

\section{Introduction}

It has been concluded that joint ventures can lead to positive effects such as lowering the cost, improving company's competitive position and facilitating organizational learning [1]. Many investors and entrepreneurs choose to take advantage of these aspects, using joint ventures to expand overseas markets and explore investment opportunities. However, Zheng (2014) announces that despite the extensive use of international joint ventures, many of them failed to achieve their goals either in financial aspects or in competitive aspects [2]. One of the limitations of joint ventures is that there are some differences in resources, objectives, interests and other aspects among stakeholders. The resulting cross-cultural conflicts are a major problem for most of the joint ventures. Therefore, emphasis is laid upon the cause of cross-cultural conflicts and appropriate corresponding strategies.

Typically, perceptual differences, lack of cultural awareness and fail to coordinate cultural differences are three major theories aiming to explain the cause of cross-cultural conflicts [3]. For the corresponding strategies, the Adaptive Co-Management (ACM) theory is a relatively effective scheme. So to what extent can ACM theory helps companies to manage cross-culture conflicts and therefore brings benefits to the whole company? How will the limitations of the theory influence the company in reality? This article will study these two questions based on the culture system of FAW-Volkswagen and the practical experience of Audi sales division separately.

The reason for choosing FAW-Volkswagen and Audi as samples for this paper is that according to a report in the US Fortune magazine in 2016, Chinese companies which are listed in the world top 500 enterprises survive an average life expectancy of only 33.37 years, well below the average level of other countries. Relatively, FAW-Volkswagen has had a history of nearly 30 years since its establishment in 1991 while China FAW has experienced nearly 70 years but still has strong competitiveness. As one of history's most famous auto industry companies in China, FAW-Volkswagen not only kept the excellent product quality, but also succeeded in absorbing partner company's cultural advantage in the process of forming a joint venture with the German company. The well-integrated corporate culture between FAW and Volkswagen Konzern Group is 
believed to be the foundation of their collaboration and their planning of 'Production and marketing plans for millions of vehicles' in 2007 [4]. Therefore, FAW-Volkswagen is supposed to have a relatively more comprehensive control system and contains more information for the analysis related to cross-culture management.

\section{Literature Review}

\subsection{Basic idea}

The idea of ACM can be defined as a dynamic management method that emphasizes learning while doing, aims to set up linkage between stakeholders [5] and continuously revises institutional arrangements according to actual performance. It has been summarized that cooperation and effective communication are part of the base of ACM theory [6].

ACM is suitable for complex and unknown environments or situations where the necessary connections between stakeholders have not been well established yet [6]. Moreover, the article also mentions that social learning which is part of the ACM systems can greatly exert its effect in the situation where stakeholders do not share resources and different interest objectives or there is a lack of agreement and collaboration. Thus, the theory will probably be helpful for the cross-culture conflict management within international joint ventures. Colfer (2005) points out that one of the characters of companies applying ACM is that they are likely to involve more stakeholders in the decision-making process in order to balance the power between stakeholders [7]. This can create a fairer platform for various groups of stakeholders to express their opinion and demand and thus reduce the possibility of serious conflicts between stakeholders. Thus, ACM probably contains an idea of decentralization, avoiding top-down structure which is criticized by Armitage et al. (2009) as ineffective at identifying risks and uncertainties in specific areas [8].

\subsection{Four major ACM principles}

After implementing an extensive review of articles related to ACM, Islam et al. (2018) summarizes that there are four principles being mentioned repeatedly in these literatures which are 'communication and collaboration', 'social learning', 'shared right and responsibility' and 'building adaptive capacity and resilience' separately [6]. The theories they have collated are listed and explained as follow to act as theoretical basis of this paper.

\subsubsection{Communication and collaboration}

The idea ACM has put much emphasis on efficient communication and collaboration between stakeholders as it is important for part of ACM's target to involve more stakeholders in the process of decision-making. For the communication aspect, it is underlined that attention should be paid to both horizontal and vertical communication [6]. The difference between these two kinds of communication is whether the communicatees are existing stakeholders or emerging stakeholders. Moreover, in order to provide more chances for effective collaboration, ACM usually requires relevant systems or committees to be established [9].

\subsubsection{Social learning}

Bandura and Albert (1977) defines social learning as reflections toward the influence of individual cognition, behavior and social environmental factors and their interactions [10]. ACM aims to create a virtuous circle of which companies are able to learn through the process of collaboration and the pattern of 'learning-by-dong'. This may promote the company's ability to generate new knowledge more frequently as well as provide assistance in facilitating the strategies associated with improving communication and collaboration. Moreover, 'learning-by-doing' is the core of the concept 'adaptive' contained in the ACM. The mode of 'learning-by-doing' requires that after stakeholders have reached a joint decision, processes including evaluate the results, learn from experience and make adjustments be followed to ensure continuous improvement. Islam et al. (2018) also mentions the suitable situation for the application of social learning includes where stakeholders do not share resources, have different interest objectives, or there is a lack of 
agreement and collaboration [6].

\subsubsection{Shared right and responsibility}

In order to balance the power between different groups of stakeholders, ACM encourages companies to seek for effective methods to share the right and responsibilities. In practice, companies usually manage to achieve this target through empower the stakeholders to participate relevant issues. The main purpose for this kind of strategy is to improve the management of shared resources through decentralization [6]. Besides, it is important for companies to draw clear boundaries of power so that the unnecessary conflicts can be avoided [11]. In all, the main idea of this principle can be separated in to decentralization and resource management two aspects. Decentralization aims to allow more stakeholders to be involved in the decision making process while the improved resource management lays the foundation for a more efficient and economical operation.

\subsubsection{Building adaptive capacity and resilience}

These principles can be regarded as part of the objectives and outcome of ACM [6]. If considering the concept of ACM literally, it is a combination of 'adaptive', 'collaboration' and 'management' three words. Therefore, part of the ACM's origin goals ought to be cultivating the company's ability to adapt to the changeable business environment and recover from any possible shock from the market. Based on the material studied, Islam et al. (2018) concludes that the three principles mentioned above all have a positive contribution to the company's pursuit of this target [6]. This principle might be understood in the way that while companies can conduct some financial, monetary and technical policies to deal with market fluctuations in the short-term, the adaptive capacity and resilience developed by implementing the ACM forms up the fundamental strength of the company to deal with long-term risks.

\begin{tabular}{ll} 
ACM principles and features. & \\
\hline Principles & Features \\
\hline $\begin{array}{l}\text { Communication and } \\
\text { collaboration }\end{array}$ & $\begin{array}{l}\text { Interactions, participation and pluralism, cooperation and } \\
\text { partnerships }\end{array}$
\end{tabular}

Social learning

Shared rights, responsibility and decision-making
Working and learning together, social dynamics, shared understanding and intentional learning, social capital, trust building, transfer of knowledge and skills

Decentralization and devolution, governance, institution building, power sharing, empowerment, negotiation and conflict management
Building adaptive capacity and resilience
Complex systems thinking and problem solving, joint planning and visioning, social-ecological system complexity and uncertainty

Figure 1 ACM principles and features

Figure 1 displayed above is summary about the four main ACM principles made by Islam et al. (2018). Their work is cited here for an intuitive demonstration of the principles.

\subsection{Barriers to the effective implementation of the ACM theory}

Despite the fact that ACM has many positive influences theoretically, there are many factors which limits the role that theory can play in practice. These elements which are probably keys to a successful implementation of ACM theories have been studied by researchers and summarized in to 


\subsubsection{Differences in the power between stakeholders}

The problem of unequal power among stakeholders is one of the most mentioned barriers to the effective implementation of ACM theory. Some stakeholder groups with higher power will influence the overall decision-making process and governance of enterprises and therefore refrain the less powerful participants from the decision-making group of an enterprise [6,12, 13]. The stakeholder groups which bear a significant influence on company's final decision are tend to act in a sense of centralization and keeping other stakeholders from participating the context of strategic planning. These behaviors are contrary to the original intention of the ACM theory to promote cooperation, communication, and take the needs and capabilities of more stakeholders in to consideration. Furthermore, the interest competition and distrust among stakeholders and the fact that the right of some stakeholders with less power to participate in the resolution exist in name only will undoubtedly limit the effect of the whole social learning process [6]. The problem may even extend to the information sharing aspect as power differences can affect stakeholders' ability to access some crucial information [12]. Therefore, it is clear that the companies should distribute the power carefully.

\subsubsection{Relatively higher cost}

Islam et al. (2018) points out that the implementation of ACM is time-consuming and requires substantial resources. As what is mentioned in the 'communication and collaboration' principle, the implementation of ACM usually requires support from specifically established systems or committees [6]. Employees may also need to be trained to fully understand the functions and rules of ACM. Furthermore, in order to ensure the efficient communication and collaboration within the company, enormous time and energy ought to be paid on the management of related aspects and this may even have a negative effect on the company's cooperation [12]. Thus, a carefully cost-benefit analysis should be taken to make sure that the ACM system is able to bring considerable improvement to the whole company.

\subsubsection{Lack of independence between stakeholders}

This sector is partly associated with the power differences sector as it is mainly caused by problems related to decentralization such as corruption and collusion among stakeholders which skew the system to the point where governance fails [14]. Innes (2004) also makes it clear that effective collaboration will only take place where stakeholders continuously seeking for ways to satisfy their own interest [15]. Therefore, efforts should be paid to increase the independence of interest between stakeholders so that the risk of different groups of stakeholders work together to hatch a plot during the decision-making process can be reduced to an acceptable level.

\subsection{Value of the research}

Former researchers have already managed to established a relatively complete ACM theoretical system. However there is a lack of concrete description like how can these theoretical ideas fit into the actual corporate culture. Therefore, this article takes the example of FAW-Volkswagen and its Audi sales division to analyze the effectiveness of applying ACM to practical situations.

Figure 2 offers a conceptual framework of FAW-Volkswagen and Audi's governance to analyze how can the ACM theory introduced to explain the company's management. The information displayed in this figure is going to be discussed in the following section. The figure is constructed based on the framework displayed in Islam et al., 2018. 


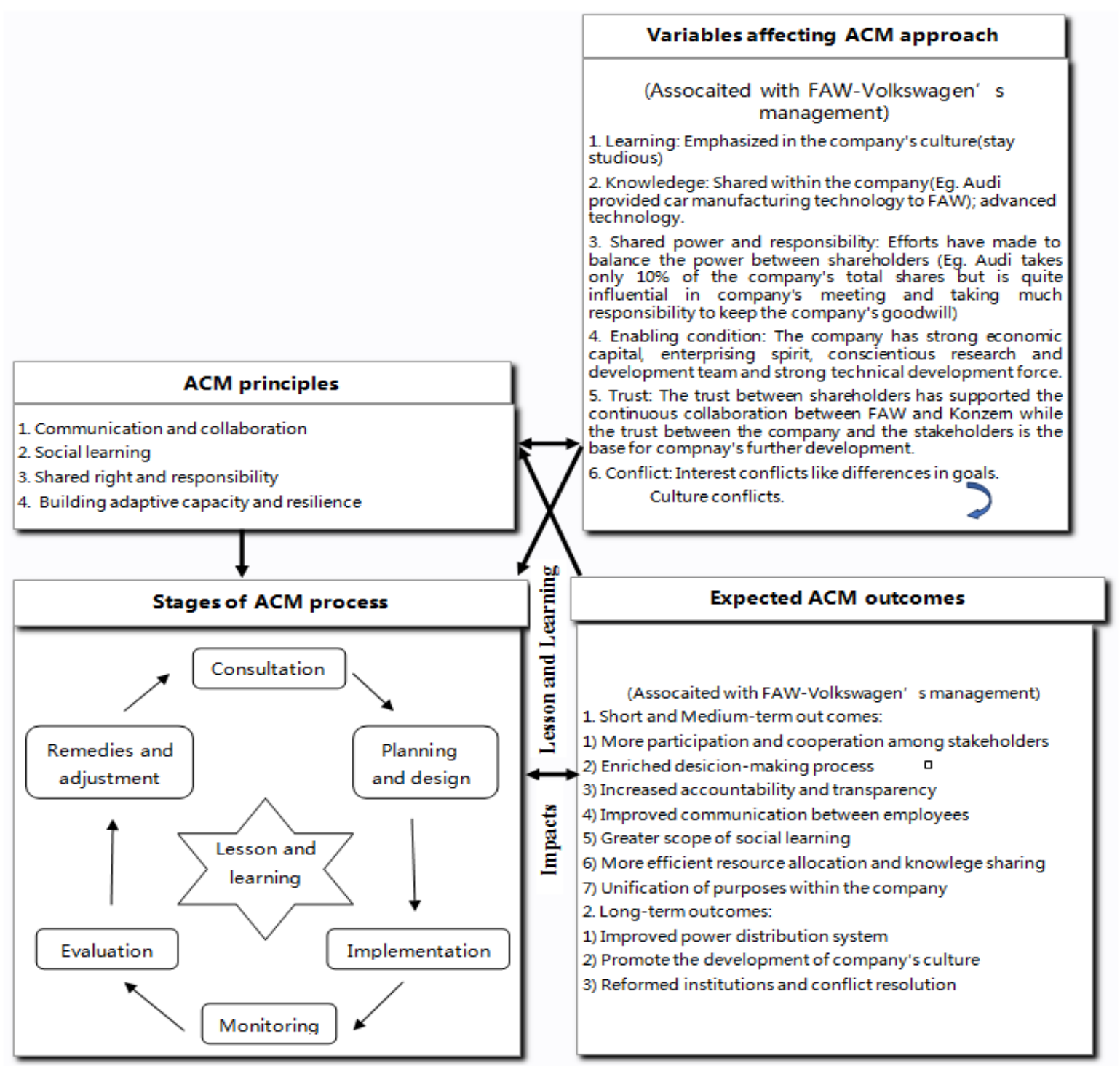

Figure 2 The conceptual framework

\section{Detailed Case Study}

\subsection{Background of the company}

The following information is collected from official website of FAW-Volkswagen and Audi:

FAW-Volkswagen was established in February 1991, with China FAW holding 60\% of the shares and Germany Volkswagen Konzern holding the rest 40\% [16]. With a registered capital 7.812 billion, FAW-Volkswagen is China's first modern car industry base constructed based on economic scale. On May $15^{\text {th }}, 1988$, FAW and Audi signed a contract related to the transfer of technology in Changchun which not only brought a qualitative improvement to China's automobile manufacturing industry but also initiated the long-term collaboration between the two companies [17]. After more than three decades of development, FAW-Volkswagen still keeps its superior position in China's auto industry, capturing about 9\% of total Chinese vehicle market share in 2014. By the end of 2018, the company also managed to raise its production capacity to the level that can achieve the annual output of 2 million sets. Audi, one of the main shareholders of FAW-Volkswagen, also perform sales in the Chinese market as a brand of FAW-Volkswagen. With nearly 3\% of the Chinese vehicle market share captured by Audi alone in 2014, it can be concluded that Audi is one of the key brands of FAW-Volkswagen and Audi has achieved a satisfying result in expanding the Chinese market through the methods of joint venture (refer to table 1). 
Table 1 FAW-Volkswagen and Audi's market share

\begin{tabular}{|c|c|c|c|c|c|c|c|}
\hline year & 2012 & 2013 & 2014 & 2015 & 2016 & 2017 & 2018 \\
\hline FAW-Volkswagen's market share & $8.3 \%$ & $8.4 \%$ & $9.0 \%$ & $7.8 \%$ & $7.7 \%$ & $7.2 \%$ & $8.8 \%$ \\
\hline Audi's market share & $1.8 \%$ & $2.3 \%$ & $2.6 \%$ & $2.4 \%$ & $2.2 \%$ & $2.0 \%$ & \\
\hline
\end{tabular}

Source: http://data.chinabaogao.com [18]

\subsection{The main aspects of the cross-culture conflicts occurred within FAW-Volkswagen}

For most of the international joint ventures, differences between the culture of the countries where the participated partners originate from are usually one of the key inducements that causes intensified enterprise interior contradiction [19]. This give rise to company's attention paid on the management of cross-culture conflicts. The culture differences between German and China also pose a threat to the development of the company. Chinese people usually attach more importance to closer relationship and human kindness while Germans are more likely to perform in a rational way $[19,20]$. When such cultural differences are reflected in the operation of a Sino-German joint venture like FAW-Volkswagen, the problems will be embodied in management issues associated with the management system, business philosophy, purposes of cultural construction and the establishment of corporate relations [19]. For example while Germans tend to regard the pursuit of profit maximization as the ultimate value goal of the enterprise, Chinese enterprises might focus more on the relationship and flexibility. The differences in the pursuing goals may lead to interest conflicts during the cooperation and increase the likelihood of disagreement among stakeholders. Since these raised problems are quite similar to the situation where is suitable for the application of the ACM theory, this paper will compare the company's culture management policies with the ACM theories to analyze the existing policies available for cross-culture conflict management and other possible application of ACM to FAW-Volkswagen's current situation.

\subsection{FAW-Volkswagen's company culture}

Information about establishment of FAW-Volkswagen's culture policies provides an overview of their attitude toward the importance of control and their methods taken for conflict management.

FAW-Volkswagen separate the main idea of the company's culture in to five sections.

The first part is about the company's mission, FAW-Volkswagen defines their target and responsibility as to 'create value classic cars, provide excellent travel services and promote the harmony between people, car and society'. FAW-Volkswagen announces that the company is aiming to drive the whole value chain to create value together, provide customers with the best products and services and actively promote the development of China's automotive industry.

Secondly, FAW-Volkswagen expresses their vision as to become the most advanced automobile enterprise in China and the most competitive and vivid company to work in and collaborate with. This section of culture contains two parts of ideas which focuses on the industry level and the company level separately. For the industry level, the company's vision means to improve its goodwill and ability to response to changes as well as form up a powerful value-chain system. When it comes to the company level, the company's vision expresses their expectation to create a working environment that encourages creativity and positive competition among employees and keep an effective collaboration with the company's partners and stakeholders.

Thirdly, FAW-Volkswagen emphasizes that 'honest' and 'respect' are two main concepts of their core value. The company hopes to attract more stakeholders and provide security for their long-term development through abiding by these two basic principles.

Fourthly, FAW-Volkswagen summarizes their enterprise spirit into 'studious', 'progressive', 'collaborative' and 'creative' four aspects. The idea of 'studious' is associated with the company's effort made to improve firm's ability to create more value. FAW-Volkswagen hopes that through continuous learning and innovation, enterprises can maintain the flexibility of management system and keep the regular upgrade in technology. Being 'progressive' means never be satisfied with what have already been achieved. It represents the company's requirement on its employees to keep learning and searching for shortages. Being ‘collaborative' and 'creative’ expresses the company's 
attitude toward the task solving issues. Employees are expected to complete tasks through collaboration (including internal collaboration with colleagues and external collaboration with partners) and creative thinking. This may help forming up a sense of teamwork within the company as well as broadening cognitive horizon to develop new problem solving techniques.

Finally, the business policy of the FAW-Volkswagen is defined to consist of 'market leading', 'management and innovation', 'quality' and 'technology' four contents.

All the information related to FAW-Volkswagen's corporate culture above is available on the company's official website [16].

Based on the achievements of cultural construction FAW-Volkswagen has made, it can be concluded that after years of exploration and improvement, the company has managed to collect their ideas about corporate culture and set up a systematic theory. Compared FAW-Volkswagen's culture system with the ACM theory, many similarities are able to be spotted. First of all, FAW-Volkswagen's culture system puts much emphasis on the importance of communication and collaboration with stakeholders from both inside and outside of the company. This meets the requirements of the 'communication and collaboration' principle of the ACM as both horizontal and vertical communication are emphasized. Moreover, FAW-Volkswagen' culture also encourages employees to focus on learning and creativity which is part of the idea of the 'social learning' principle. In the vision section, the company shows their concern on the enterprise's ability to cope with changes which is also mentioned in the "building adaptive capacity and resilience" principle.

\subsection{Analysis on actual operation of FAW-Volkswagen-Take the case of FAW-Volkswagen Audi sales division as an example}

Established in the beginning of 2006, FAW-Volkswagen Audi sales division is a subordinate division of FAW-Volkswagen which is responsible for the sales and service of all domestic and imported models of Audi within the China market [21]. As what is mentioned in the background section, Audi's products are quite competitive in Chinese market and the brand itself has also become part of FAW-Volkswagen's image. Therefore, the situation of Audi sales division ought to be representative as a sample selected to study FAW-Volkswagen's cross-culture conflicts management.

First, concerning the problems related to equity allocation, although it is not a cross-culture conflict itself, imbalanced power between shareholders usually leads to this kind of conflict. Despite the fact that Audi takes only $10 \%$ of the total shares of FAW-Volkswagen, it doesn't mean that Audi only have $10 \%$ of the total voting power which is quite special for joint ventures. The head of Audi China, Heinz-Hermann Stark announces that although Audi takes only $10 \%$ of the total shares, neither does FAW-Volkswagen regard Audi as $10 \%$ weighted partner, nor does Audi only make effort to manage $10 \%$ of the total work [21]. It is emphasized that FAW rarely takes its advantage as the major shareholder nor does Audi and other shareholders with less percentage of the company's stock use their specific technology resources to force the major shareholders to make a compromise [21, 22]. The information introduced above partly explains the power distribution scheme of FAW-Volkswagen. The company probably decided to separate its power more evenly through reducing the influence of equity. This method is probably an attempt to fulfill the idea of balancing the power between stakeholders announced by ACM theory. It is believed to an effective way as the performance of FAW-Volkswagen is so far competitive enough and Audi sales division is truly involved in the decision-making process [21, 22], enjoying the shared right as well as taking part of the responsibility. However, the method may have some limitation as during the period between 2014 and 2017, the market share of both FAW-Volkswagen and Audi sales division experienced a sustained decline. Although there is little formal source of information related to this recession, there is some arguments that it is because the growth rate of the car market slowed down sharply after 2014 and the low Volkswagen's shareholding ratio which make the foreign party's reluctant to invest resources and introduce models. Therefore, the low management efficiency and other problems gradually emerged which greatly reduced the original advantages of the enterprise [18]. Hence, more efforts should be paid to implement a more reasonable separation of power so 
that the sustainability of the company's operation can receive more guarantee. Fortunately, FAW-Volkswagen recovered from their dilemma and raised their market share back to around 9\% in 2018. This probably shows the company's success in building adaptive capacity and resilience.

Secondly, one of the most serious cross-culture conflicts Audi sales division was facing in the Chinese market is the problem related to indigenized product design. As a famous German automobile brand with advanced production technology and well-designed products, it is important for Audi sales division to adjust existing products to meet the needs of Chinese consumers. Audi sales division managed to solve these problems through effectively communicating and collaborating with domestic managers and market researches. A typical example is the lunch of Audi A6 in China. According to the information displayed on Audi's official website, the Audi A6 model launched in China is not the same as the model launched in Europe. After discussing with the Chinese partners, Audi finally adjust the length of wagon to satisfy Chinese consumers' requirements [21]. This shows Audi's attention paid to collaboration and learning as Audi accepted the suggestion and make a risky change to the products which have already achieve a great success in the European market.

Finally, in order to ensure that all the employees of the enterprise have a relatively full understanding of corporate culture so that the risk of cross-culture conflicts can be controlled within reasonable range, Audi sales division invests much resources on the employees' training programs [21] and setting up committees specific for culture management [22]. Through improving the degree of internal understanding among employees, discussion related to any topic within the organization will become more efficient. One of the benefits brought by this change is that it can help setting up a self-perpetuating learning system within the company [21]. Therefore, it may pave the way for a 'learning-by-doing' system to support the continuous improvement of the company.

\section{Conclusion}

This paper focuses on the study of the 'Adaptive Co-management' theory based on the research made by former scholars. Through the comparison between a successful company case and the theory in the actual operation process, this paper also makes a research on the impact of theory for the company's cultural management and the ability to deal with cross-cultural conflicts in the practical application. The four main principles of the ACM have been introduced, emphasizing the theory's emphasis put on the importance of collaboration, communication, learning, ability to adapt fluctuation, resilience and balance of power. FAW-Volkswagen is chosen to be the object for comparison as the company is undoubtedly one of the most successful Sino-foreign joint ventures with a history of more than thirty years. After analyzing FAW-Volkswagen's culture system, many similar aspects to the ACM are spotted. Part of the real practical cases about the FAW-Volkswagen Audi sales division is listed to support the effectiveness of implementing ACM in managing the cross-culture conflicts. The fact that FAW-Volkswagen's power distribution is not effectively enough is mentioned in the article. However, due to the lack of evidences, further researches are not made in this paper.

\section{References}

[1] Kogut, B. (1988). JOINT VENTURES: THEORETICAL AND EMPIRICAL PERSPECTIVES. Strategic Management Journal (1986-1998), 9(4), 319-332.

[2] Zheng, X., \& Larimo, J. (2014). Identifying Key Success Factors for International Joint Ventures in China: A Foreign Parent Perspective from Finnish Firms. E+M Ekonomie a Management, 17(2), 106-119.

[3] Conley, S., \& Urch, G. (1989). Cross-cultural education: Breaking through cultural barriers (ProQuest Dissertations Publishing). Retrieved from $<$ http://search.proquest.com/docview/303773713/>

[4] Wang, T. (2009), Research on joint venture culture construction based on the case of 
FAW-Volkswagen. Tianjin University, Master's thesis.

[5] Nancy D. (2008). Adaptive co-management and the learning that leads to social innovation. Open Source Business Resource

[6] Islam, Ruhanen \& Ritchie (2018). Adaptive co-management: A novel approach to tourism destination governance?, Journal of Hospitality and Tourism Management 37 (2018)-97-206.

[7] Colfer, C. J. P. (2005). The complex forest: Communities, uncertainty, and adaptive collaborative management. Washington DC, USA: Routledge

[8] Armitage, D., Plummer, R., Berkes, F., Arthur, R. I., Charles, A. T., Davidson-Hunt, I. J., \& Marschke, M. (2009). Adaptive co-management for social-ecological complexity. Frontiers in Ecology and the Environment, 7(2), 95e102

[9] Schusler, T. M., Decker, D. J., \& Pfeffer, M. J. (2003). Social learning for collaborative natural resource management. Society and Natural Resources, 16(4), 309e326.

[10] Bandura \& A. (1977). Social learning theory. Englewood Cliffs, N.J: Prentice Hall.

[11] Carlsson, L., \& Berkes, F. (2005). Co-management: Concepts and methodological implications. Journal of Environmental Management, 75(1), 65e76.

[12] Almeida, J., Costa, C. Silva, F. (2018). Collaborative approach for tourism conflict management: A Portuguese case study. Land Use Policy, 75 (2018) 166-179

[13] Gray, B., 1989. Collaborating: Finding Common Ground for Multiparty Problems. Jossey-Bass, San Francisco.

[14] Batterbury, S. P. J., \& Fernando, J. L. (2006). Rescaling governance and the impacts of political and environmental decentralization: An introduction. World Development, 34(11), $1851 \mathrm{e} 1863$.

[15] Innes, J.E., 2004. Consensus building: clarifications for the critics.

[16] FAW-Volkswagen, 2020， www.faw-vw.com/summary; www.faw-vw.com/culture.html, accessed on 20.02.2020.

[17] Audi, 2020, www.audi.cn/cn/web/zh/audi_brand/audi_about/enter_faw-vw.html, accessed on 20.02.2020

[18] Information on: http://jingzheng.chinabaogao.com/qiche/09132953t2017.html, accessed on 20.02.2020

[19] Zhang, L., (2009). Study of FAW Multi-culture Conflict and Integration. Tianjin University, Master's thesis.

[20] Zhang, Y. \& Wang, H. (2013). Study on Sino-German Cross-cultural Management of FAW-Volkswagen. Management Forum, (2013) 07-00501.

[21] Zhang, X., (2012). Study on Cross-culture Management of FAW-Volkswagen Audi Brand. Jilin University, Master's thesis

[22] Wang, Y., (2018), Study on Cross-culture Management Strategy of FAW-Volkswagen Audi. Auto maintenance \& Repair, 05A, 12-13 